\title{
Multiple sclerosis in Australia and New Zealand: are the determinants genetic or environmental?
}

\author{
D H Miller, S R Hammond, J G McLeod, G Purdie, D C G Skegg
}

\begin{abstract}
The prevalence of multiple sclerosis (MS) has been recently reported from nine regions of Australia and New Zealand. There is a marked variation of prevalence with latitude. MS is seven times more common in southern New Zealand than in tropical Queensland. On current evidence, it is suggested that in both countries this variation is predominantly due to environmental rather than genetic factors.
\end{abstract}

While it is clear that both environmental and genetic factors are involved in the aetiology of multiple sclerosis (MS), their relative contribution to its geographical distribution in white populations is less certain.

In a review of the literature up to about 1980 , Acheson said "that within people of British and North and Central European stock the risk of developing multiple sclerosis varies by a factor of 10 , and perhaps by a factor of 20 according to geographical location". ${ }^{1} \mathrm{He}$ notes the general relationship of this risk with latitude, and concludes that such data "provide one of the principal arguments for the existence of an important environmental factor in the aetiology of MS".

It has been suggested more recently that genetic factors may influence the distribution of MS in white populations. First, it has been proposed that Scots and Scandinavians have a greater susceptibility to MS than white populations who have traditionally lived at lower latitudes, and there is evidence in the United States that a higher proportion of the population are of Scandinavian origin in regions of high MS prevalence. ${ }^{2}$ Secondly, in the United Kingdom, the regional population frequency of the MS-associated HLA-DR2 antigen has been reported to correlate with the prevalence of $\mathrm{MS}^{3}$ (DR2 is the HLA antigen most closely associated with MS in the majority of case-control studies in white populations). ${ }^{45}$

In the early 1980s, MS prevalence studies were carried out in nine separate regions of Australia and New Zealand. ${ }^{6-10}$ In all regions, the predominant ethnic population is white of United Kingdom ancestry. The nine regions surveyed span a latitude of $27^{\circ}$. We now present a collation of these studies, with particular emphasis on the relationship of the disease distribution to latitude, Scottish ancestry and population DR2 frequency.

\section{Methods}

Prevalence rates for all cases of MS (including possible cases) in the nine regions were derived from recently published studies. ${ }^{6-10}$ Prevalence data in each Australian region was 30 June 1981; in Waikato and Otago-Southland it was 24 March 1981, and in Wellington 30 June 1983.

The prevalence rate for each region was age adjusted to the 1981 Australian population to obviate any differences consequent on variation in the age structure of the population of each region surveyed. In calculating the prevalence figure for each region, the population used was the total non-Aboriginal/Torres Islander population in Australian regions and the total non-Maori population in New Zealand regions. This adjustment was made because MS appears to be very rare in these indigenous populations: $:^{8-10}$ it is particularly important in northern New Zealand, where Maoris account for a sizable minority of the population. Where a region (for example, tropical and subtropical Queensland) extended over several degrees of latitude, the mean latitude or "population centre of gravity" (as reported in the Queensland study ${ }^{6}$ ) was used.

As a crude indicator of Scottish ancestry, the proportion of surnames beginning with "Mc" or "Mac" was recorded from telephone directories in each of the nine regions. The population frequency of DR2 was derived from healthy white blood donors who were seen at the following Tissue Typing laboratories: the Australian Red Cross Societies in Sydney and Adelaide, The Royal Melbourne Hospital in Melbourne, the Princess Alexandra Hospital in Brisbane, and the Regional Blood Services in Auckland and Wellington. The DR2 frequency in each of these cities was correlated with latitude (of the cities), and with MS mortality rates which in each case were available for a larger geographical region within which DR2 frequency was recorded in the major city. ${ }^{112}$ The Australian "Mc/Mac" and DR2 data has been previously published, ${ }^{1013}$ but not that from New Zealand. Pearson's correlation coefficients were used for statistical analysis.

\section{Results}

There was a strong correlation of the prevalence of MS (all cases) with latitude ( $r=$ $0.89, p=0.001$, with an almost seven-fold difference in prevalence between tropical Queensland and southern New Zealand (table 
Table 1 Age standardised prevalence of MS (all cases) in Australia and New Zealand according to latitude $\dagger$

\begin{tabular}{lllll}
\hline Survey area & $\begin{array}{l}\text { Latitude } \\
\left({ }^{\circ} S\right)\end{array}$ & $\begin{array}{l}\text { Patients } \\
\text { (number) }\end{array}$ & $\begin{array}{l}\text { Prevalence }^{\star} \\
\left(\text { per } 10^{5}\right)\end{array}$ & $95 \% C I$ \\
\hline $\begin{array}{l}\text { Queensland, Australia } \\
\quad \text { Tropical }\end{array}$ & & & & \\
$\quad$ Subtropical & $18 \cdot 9$ & 48 & $12 \cdot 4$ & $9 \cdot 6-16 \cdot 4$ \\
Perth, Australia & $26 \cdot 9$ & 356 & $21 \cdot 1$ & $19 \cdot 0-23 \cdot 4$ \\
Newcastle, Australia & $32 \cdot 0$ & 264 & $30 \cdot 1$ & $26 \cdot 5-34 \cdot 1$ \\
Adelaide, Australia & $32 \cdot 9$ & 142 & $36 \cdot 2$ & $30 \cdot 6-42 \cdot 8$ \\
Waikato, New Zealand & $34 \cdot 9$ & 310 & $32 \cdot 1$ & $28 \cdot 6-36 \cdot 0$ \\
Wellington, New Zealand & $38 \cdot 0$ & 77 & $29 \cdot 6$ & $23 \cdot 4-37 \cdot 0$ \\
Hobart, Australia & $41 \cdot 3$ & 236 & $75 \cdot 3$ & $65.9-86 \cdot 0$ \\
Otago-Southland, New Zealand & $42 \cdot 8$ & 125 & $75 \cdot 8$ & $63 \cdot 4-90 \cdot 7$ \\
& $46 \cdot 2$ & 226 & $81 \cdot 7$ & $72 \cdot 5-93 \cdot 3$ \\
\hline
\end{tabular}

$\mathrm{CI}=$ confidence intervals

$\star=$ The denominator populations consist of non-Aboriginal/Torres Strait Islanders in Australia and non-Maoris in New Zealand. All rates are age-standardised to the 1981 Australian population.

†Adapted from Hammond $\mathbf{S R}^{10}$

1, fig). The prevalence in the three regions which are more than $40^{\circ} \mathrm{S}$ is in each case more than twice that found in any of the regions which are less than $40^{\circ} \mathrm{S}$.

The proportion of $\mathrm{Mc} / \mathrm{Macs}$ did not show a significant correlation with latitude $(r=0.38$, $\mathrm{p}=0.31$ ), and was relatively constant throughout, except for a higher proportion in the south of the South Island of New Zealand, that is Otago-Southland (table 2).

There was no correlation of the population frequency of DR2 with latitude $(r=-0.60$, $\mathrm{p}=0.21$ ) or with regional mortality from MS $(r=-0.59, p=0.22$; table 3$)$. There was, however, a significant correlation of latitude with mortality $(r=0.86, p=0.03)$.

Table 2 Proportion of population with names beginning with "Mc" or "Mac" in the telephone directories of each survey area

\begin{tabular}{|c|c|c|}
\hline Survey area & $\begin{array}{l}\text { Latitude } \\
\left({ }^{\circ} S\right)\end{array}$ & $M c / M a c$ \\
\hline \multicolumn{3}{|l|}{ Queensland, Australia } \\
\hline Tropical & $18 \cdot 9$ & $3 \cdot 3^{\circ} \mathrm{o}$ \\
\hline Subtropical & 26.9 & $3.3 \%$ \\
\hline Perth, Australia & $32 \cdot 0$ & $2 \cdot 4^{\circ} \%$ \\
\hline Newcastle, Australia & 32.9 & $3.0 \%$ \\
\hline Adelaide, Australia & 34.9 & $2.1 \%$ \\
\hline Waikato, New Zealand & $38 \cdot 0$ & $3 \cdot 3 \%$ \\
\hline Wellington, New Zealand & $41 \cdot 3$ & $3.8 \%$ \\
\hline Hobart, Australia & $42 \cdot 8$ & $2.6 \%$ \\
\hline Otago-Southland, New Zealand & $46 \cdot 2$ & $5.5 \%$ \\
\hline
\end{tabular}

The New Zealand figures are those of the principal city in each region, that is, Hamilton (Waikato), Wellington (Wellington) and Dunedin (Otago-Southland).

Table 3 Relationship of regional DR2 frequency, MS mortality and latitude in Australia and New Zealand

\begin{tabular}{lllll}
\hline Region & $\begin{array}{l}\text { Latitude } \\
\text { (region) }\end{array}$ & Mort. $\neq$ & $\begin{array}{l}\% \text { DR2 } \\
\text { Positive } \\
\text { (numbers) }\end{array}$ & $\begin{array}{l}\text { Latitude } \\
\text { (city) }\end{array}$ \\
\hline Queensland, Australia & 25 & 0.36 & $30(95 / 317)$ & 27.5 \\
New South Wales, Australia & 34 & 0.46 & $27(112 / 421)$ & 33.9 \\
South Australia, Australia & 35 & 0.59 & $30(40 / 132)$ & 34.9 \\
Auckland-Northland, New Zealand & 37 & 0.76 & $23(51 / 220)^{\circ}$ & 36.9 \\
Victoria, Australia & 38 & 0.75 & $28(57 / 201)$ & 37.8 \\
Wellington-Nelson, New Zealand & 41 & 1.16 & $25(57 / 229) \#$ & 41.3 \\
\hline
\end{tabular}

ऋThese figures are taken from the major city in each region, that is, Brisbane, Queensland, Sydney, New South Wales; Adelaide, South Australia; Auckland, Auckland-Northland; Melbourne, Victoria; Wellington, Wellington-Nelson.

The mean latitude (to the nearest degree) of the population "centre of gravity" for each region.

†Th mean latitude (to the nearest degree) of the population "centre of gravity" for each region.
†MORT $=$ average annual MS mortality per $10^{5}$, age-standardised to the 1981 Australian $\ddagger$ MORT $=$ average annual MS mortality per $10^{5}$, age-standardised to the 1981 Australian
population. Australian figures are averages during the period $1971-1980$ and are for nonAboriginal/Torres Strait Islander population; New Zealand figures are averaged during thi period 1970-1981 and are for the non-Maori population.

G Woodfield-personal communication.

\#J Dagger-personal communication.

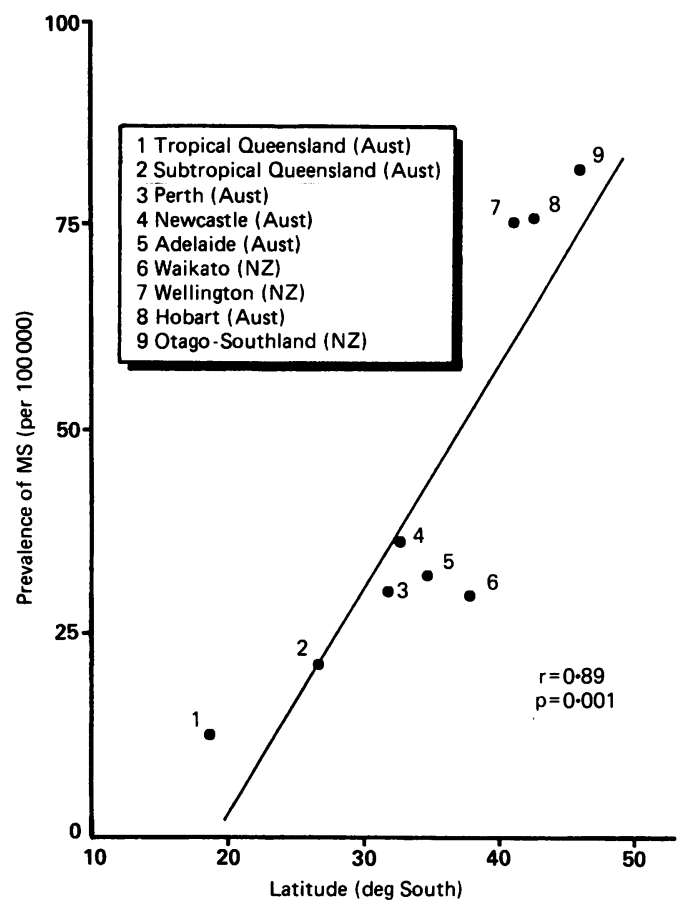

Figure The relationship of prevalence of multiple sclerosis with latitude in Australia and New Zealand.

\section{Discussion}

The validity of comparing several studies performed independently of each other may be questioned. For a number of reasons, we think that in this case the comparison is valid. First, the studies were all performed in close temporal proximity. This is important, since there has been a considerable increase in the prevalence of MS in many regions over recent decades-indeed, with the exception of South Australia, the prevalence rates reported in Australian and New Zealand surveys in the 1960 s were about $30-60 \%$ less than 1980 s rates from the same regions ${ }^{14-17}$ (although a similar relationship of MS prevalence with latitude was present in the 1960s).

Secondly, although the same diagnostic classification system was not used in all regions, all systems were similar in that clinical symptoms and signs alone were analysed, that is evoked potentials and cerebrospinal fluid (CSF) results were not considered in the classification of cases; furthermore, all cases (including possibles) were analysed, which avoided the problem of differences with individual diagnostic categories between the classifications. Thirdly, there was a high standard of medical care and surveillance in each region.

Several factors may account for the increasing prevalence of $M S$ in recent decades; improved diagnosis of early cases, ${ }^{6}$ and increased duration of survival are likely to be important. ${ }^{18}$ Improved case ascertainment with a second survey is also likely to have an effect. ${ }^{18}$ Wellington, ${ }^{17}$ Perth, ${ }^{15}$ Newcastle, ${ }^{15}$ Adelaide $^{16}$ and Hobart ${ }^{15}$ were being studied for a second time; a previous study of smaller regions within Queensland had been undertaken;14 Otago-Southland and Waikato were being studied for the first time. 
Adelaide and Waikato had lower prevalence rates than might have been expected if there had been a simple relationship of prevalence with latitude. In Adelaide, it was suspected that there was an underascertainment of patients among the overseas-born population, and indeed, when the analysis was confined to the Australian-born population only, the relationship between $M S$ prevalence and latitude within Australia in 1981 showed no anomalies. ${ }^{10}$ In Waikato, there is likely to be an effect of "first survey underascertainment" (it is probable that case ascertainment was better in the Otago-Southland region because there has been a medical school in this region for over 100 years, with specialist neurologist services for many years). Another factor in the low Waikato figure may lie in the definition of a Maori. In the 1981 New Zealand census, Maoris were defined as people who specified themselves as being of half or more Maori origin. Using this definition, Maoris constituted $15.7 \%$ of the Waikato, $6.7 \%$ of the Wellington and $2 \cdot 4 \%$ of the Otago-Southland population. Thus among the non-Maori population as defined in 1981 , there were individuals with some (less than $50 \%$ ) Maori ancestry; it is possible that such individuals have a lower susceptibility for the development of MS, and thus may contribute to a reduced overall prevalence in this denominator population. Such an effect would clearly be most pronounced in Waikato.

Both environmental and genetic factors have been postulated to account for the geographical distribution of $M S$ in white populations. In Australia, the recent findings have been interpreted as favouring an environmental cause. In New Zealand, it has been suggested that the distribution of MS could be influenced by both environmental factors and by the pattern of Scottish migration to that country. ${ }^{8}$

The percentage of $\mathrm{Mc} / \mathrm{Macs}$ in the telephone book is a necessarily crude indicator of Scottish ancestry-indeed some Mc/Macs would be of Irish descent. Nevertheless, there was no overall relationship with MS prevalence or latitude, although in OtagoSouthland, there was the highest proportion of $\mathrm{Mc} / \mathrm{Macs}$ and as well the highest prevalence of MS of all regions. The early European settlement of this southernmost region of New Zealand was indeed predominantly Scottish. However, it is notable that both the prevalence and mortality ${ }^{12}$ of MS in Otago-Southland is only slightly higher than that in Wellington. The major change in MS prevalence and mortality ${ }^{12}$ in New Zealand occurs between the southern (that is, Wellington) and northern (that is, Waikato and Auckland) parts of the North Island. Between these regions, there is no substantial difference in the proportion of $\mathrm{Mc} /$ Macs.

Unlike the United Kingdom, there was no relationship of regional DR2 frequency with frequency of $\mathrm{MS}$ in Australia and New Zealand between latitudes $27^{\circ} \mathrm{S}$ and $41^{\circ} \mathrm{S}$. Indeed, there was a slightly higher frequency of DR2 in Brisbane than in Wellington, whereas MS prevalence and mortality is several times higher in Wellington. In Australia, it has also been found that there are no significant regional differences in the country of origin of United Kingdom migrants: notably, there is no excess of Scottish migrants in the regions of higher MS prevalence. ${ }^{13}$

To conclude, there is no evidence that the major variations in the frequency of MS in either Australia or New Zealand are due to differences in population DR2 frequency or the proportions with Scottish ancestry. It is possible that a higher proportion with Scottish ancestry in the south of the South Island of New Zealand may contribute to the slightly higher prevalence of MS in this region when compared with Wellington and Hobart. It is also possible that some other unidentified genetic factor has a more substantial influence on the disease distribution; the aetiological importance of genetic factors is beyond question and this is indeed evident from the rarity of MS amongst the indigenous populations of the two countries. It does, however, seem more likely that the major variations in disease frequency are in both countries due to environmental factors, the nature of which are undetermined.

1 Acheson ED. The Epidemiology of Multiple Sclerosis. In: Matthews WB, ed. McAlpine's multiple sclerosis. Edinburgh: Churchill Livingstone, 1985;1-46.

2 Ebers GC, Bulman D. The geography of MS reflects genetic susceptibility. Neurology 1986;36(Suppl 1):108

3 Swingler RJ, Compston DAS. The distribution of multiple sclerosis in the United Kingdom. J Neurol Neurosurg Psychiatry 1986;49:1115-24

4 Swingler RJ, Kirk PF, Darke C, Compston DAS. HLA and multiple sclerosis in south east Wales. J Neurol Neurosurg Psychiatry 1987;50:1153-5.

5 Miller DH, Hornabrook RW, Dagger J, Fong R. Class II HLA antigens in multiple sclerosis. $J$ Neurol Neurosurg Psychiatry 1989;52:575-7.

6 Hammond SR, de Wytt C, Maxwell IC, et al. The epidemiology of multiple sclerosis in Queensland, Australia. J Neurol Sci 1987;80:185-204.

7 Hammond SR, McLeod JG, Millengen KS, et al. The epidemiology of multiple sclerosis in three Australian epidemiology of multiple sclerosis in three Australian
cities: Perth, Newcastle and Hobart. Brain 1988;111:1-25.

8 Skegg DCG, Corwin PA, Craven RS, Malloch JA, Pollock M. Occurrence of multiple sclerosis in the north and south of New Zealand. J Neurol Neurosurg Psychiatry 1987; 50:134-9.

9 Miller DH, Hornabrook RW, Dagger J, Fong R. Ethnic and HLA patterns related to multiple sclerosis in Wellington, New Zealand. J Neurol Neurosurg Psychiatry 1986;49: 43-6.

10 Hammond SR. The epidemiology of multiple sclerosis in Australia. PhD Thesis, University of Sydney, 1988.

11 Hammond SR. English DR, de Wytt C, et al. The contribution of mortality statistics to the study of multiple sclerosis
in Australia. $J$ Neurol Neurosurg Psychiatry 1989;52:1-7.

12 Fawcett J, Skegg DCG. Geographic distributions of MS in New Zealand: evidence from hospital admissions and New Zealand: evidence from hos
deaths. Neurology 1988;38:416-8.

13 Hammond SR, English DR, de Wytt C, et al. The relationship between multiple sclerosis frequency and latitude in Australia. In: Battaglia MA, ed. Multiple sclerosis research. Australia. In: Battaglia MA, ed. Multiple sclerosis research.
(Proc Int Multiple Sclerosis Conference: an update on (Proc Int Multiple Sclerosis Conference: an update on
Multiple Sclerosis.) Excerpta Medica, International Congress Series 1989;843:171-7.

14 Sutherland JM, Tyrer JH, Eadie MJ, Casey JH, Kurland LT. The prevalence of multiple sclerosis in Queensland, Australia. Acta Neurol Scand 1966;42(Suppl 19):57-67.

15 McCall MG, Brereton T LeG, Dawson A, Millengen K, Sutherland JM, Acheson ED. Frequency of multiple sclerosis in three Australian cities-Perth, Newcastle and Hobart. J Neurol Neurosurg Psychiatry 1968;31:1-9.

16 Rischbieth RH. The prevalence of disseminated sclerosis in South Australia. Med J Aust 1966;1:774-6.

17 Hornabrook RW. The prevalence of multiple sclerosis in New Zealand. Acta Neurol Scand 1971;47:426-38.

18 Poskanzer DC, Prenny LB, Sheridan JL, Kondy JY. Multiple sclerosis in the Orkney and Shetland Islands. I. Epidemiology, clinical factors and methodology. $J$ Epidemiol Commun Health 1980;34:229-39. 